\title{
The Design and Analysis of Self-balancing Adjustment Implement Leveling Control System
}

\author{
Qingfeng Yang 1,2,3,a , Yehua Shang 2,b, Siyu Liu ${ }^{1,2, c}$, Fujie Zhang ${ }^{1, d}$, Yue Cong 2,e, Weiqiang Fu ${ }^{2, f}$, \\ Rui Pan ${ }^{1,2, g}$, Chunjiang Zhao ${ }^{3, h,(\varpi)}$ \\ 1.Faculty of Modern Agricultural Engineering,Kunming University of Science and \\ Technology,Kunming 650000, China ; \\ 2.National Research Center of Intelligent Equipment for Agriculture,Beijing 100097, China ; \\ 3.Key Laboratory of Agri-informatics Ministry of Agriculture,Beijing 100097, China \\ a1135756743@qq.com, bshangyh@nercita.org.cn,'1079937882@qq.com, \\ d66605115@qq.com, ${ }^{\mathrm{e}}$ congy@nercita.org.cn, ${ }^{\mathrm{f}}$ fuwq@nercita.org.cn,,g909195326@qq.com, \\ hzhaocj@nercita.org.cn
}

\begin{abstract}
This article analyzed the shortcomings of the present laser land leveling machine, when it works on the uneven land. A self-balancing adjustment control system is proposed, which attempt to expand the implement level control, so as to improve and enhance the leveling precision and efficiency. This system can automatically keep the agricultural implements balance when it works in the uneven land. Real-time roll angle of the implement was obtained be a gyroscope sensor, which fixed on the center of the implement. The controller actuate the magnetic valve according to the real-time roll angle of the implement. This study provides a method for auto leveling controlling system of agricultural implement. which can improve the flatness of the land. With this control system, the absolute roll angle of the implement, which worked on a $15^{\circ}$ slope land has decreased $47.8 \%$, the relative improvement is $18.6 \%$, and the land altitude intercept is less than $1 \%$.
\end{abstract}

Keywords: laser land leveling machine ; roll angle of the implement ; selfbalancing adjustment control

\section{Introduction}

Laser grader is the new technology of laser and hydraulic technology applied to land preparation and operation. The laser leveling technology can effectively improve the flatness of farmland and improve the utilization rate of irrigation water in farmland. It is one of the international water saving technologies. In paddy field leveling operations, it is necessary to solve the problem of attitude control of flat shovel, that means to maintain the level of balance control. As the existing trailing laser graders have only height control of the ground shovel without horizontal balance control. In view of this situation, I carried out the paddy field sand mixing control system design, and its measurement accuracy of the test and analysis. 


\section{System Design}

The laser graders designed in this study are composed of laser transmitting and receiving devices, flat shovels, plain shovel hydraulic systems, attitude sensor and controllers. The main working principle is that the laser transmitter and the laser receiver transmit the ground leveling state information to the controller. At the same time, the attitude sensor feeds the horizontal attitude degree and the inclination degree of the flat shovel to the controller. The controller receives two signals, The four-way solenoid valve controls the hydraulic system to achieve horizontal lift control of the ground shovel. The overall design of the horizontal control system for paddy field was as shown in Fig.2a

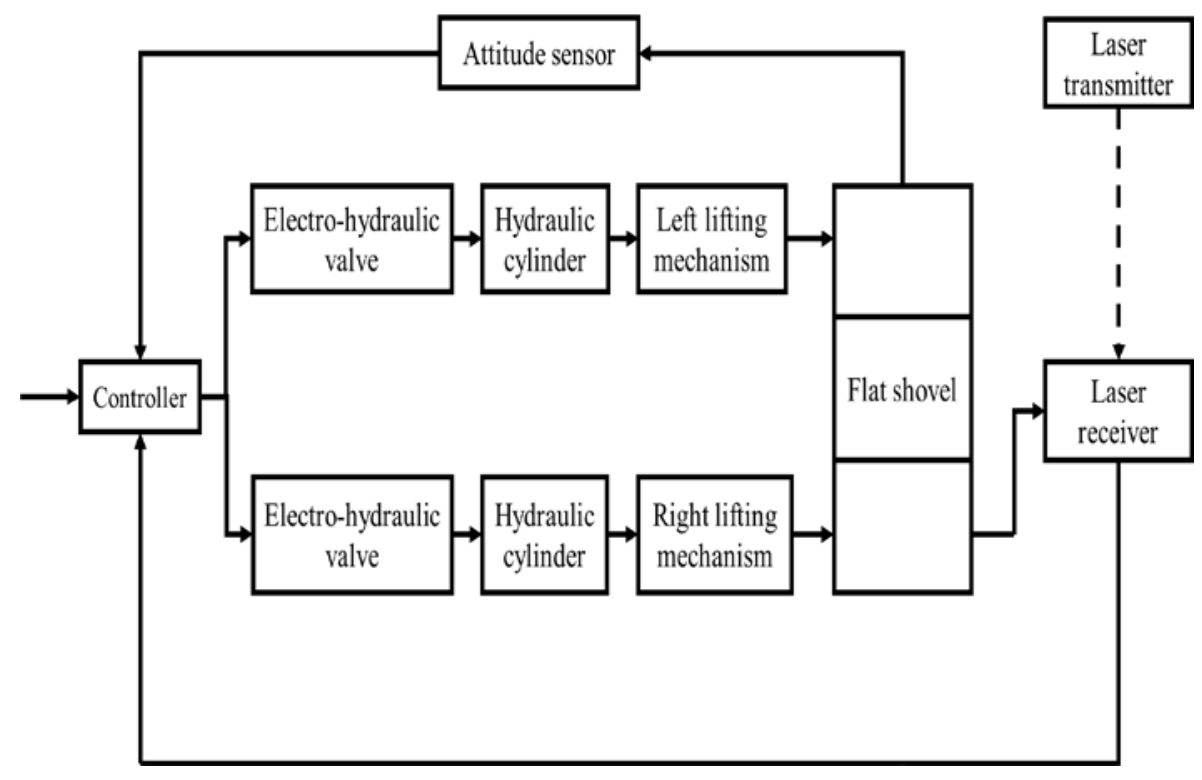

Fig.2a The overall design of the horizontal control system for paddy field

\subsection{Hydraulic System Design}

The role of the hydraulic system is to control the hydraulic oil through the directional control valve, which can drive the hydraulic cylinder to actuate the ground shovel go up and down . The hydraulic system converts the electrical signal of the control converter into mechanical control. According to the flat shovel mechanical part Action requirements, the design of hydraulic systems, to achieve a fine farmland land. Horizontal shovel hydraulic system includes oil source, valve control cylinder flat shovel lifting system, valve control motor laser receiver lift system and valve block, oil filter, hydraulic pipe and other hydraulic components, the system schematic diagram shown in Figure 2b. 


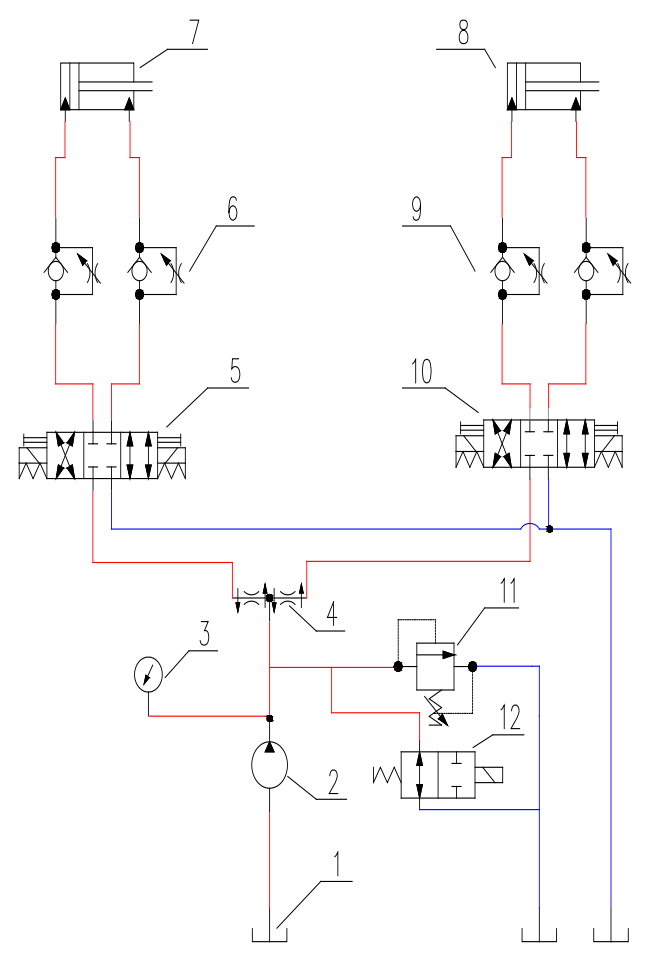

Fig.2b The schematic diagram system

1 - Fuel tank

2 - Hydraulic pump

3 - Pressure gauge

4 - splite-flow valve

5 - Left electro - hydraulic proportional directional control valve

6 - Left one - way throttle valve

7 - Left hydraulic cylinder

8 - right hydraulic cylinder

9 - right one-way throttle valve

10 - right electromechanical proportional directional valve

11 - regulator valve

12 - electromagnetic relief valve

The system uses the tractor after the power output as the pump source power, the system work pressure design in the 2.0-12.0 MPa range adjustable, consider the flow and cooling and other factors, the design tank volume of 100L. The lifting action of the ground shovel is realized by the oil control cylinder oil pipeline, using the 10-channel three-way four-way solenoid valve as the control element, the three-way four-way solenoid valve can control the hydraulic cylinder telescopic action, in order to achieve the ground shovel lifting control To meet the job needs.

\subsection{Design of Electronic Control System}


The controller developed in this study can receive the signal of the laser receiver and the signal of the attitude sensor in real time. It can output two power control signals for the solenoid valve in the valve control cylinder and the valve control motor circuit. At the same time, And automatic control function switching. The manual flow and manual control flow charts are as follows in Figure 2c.

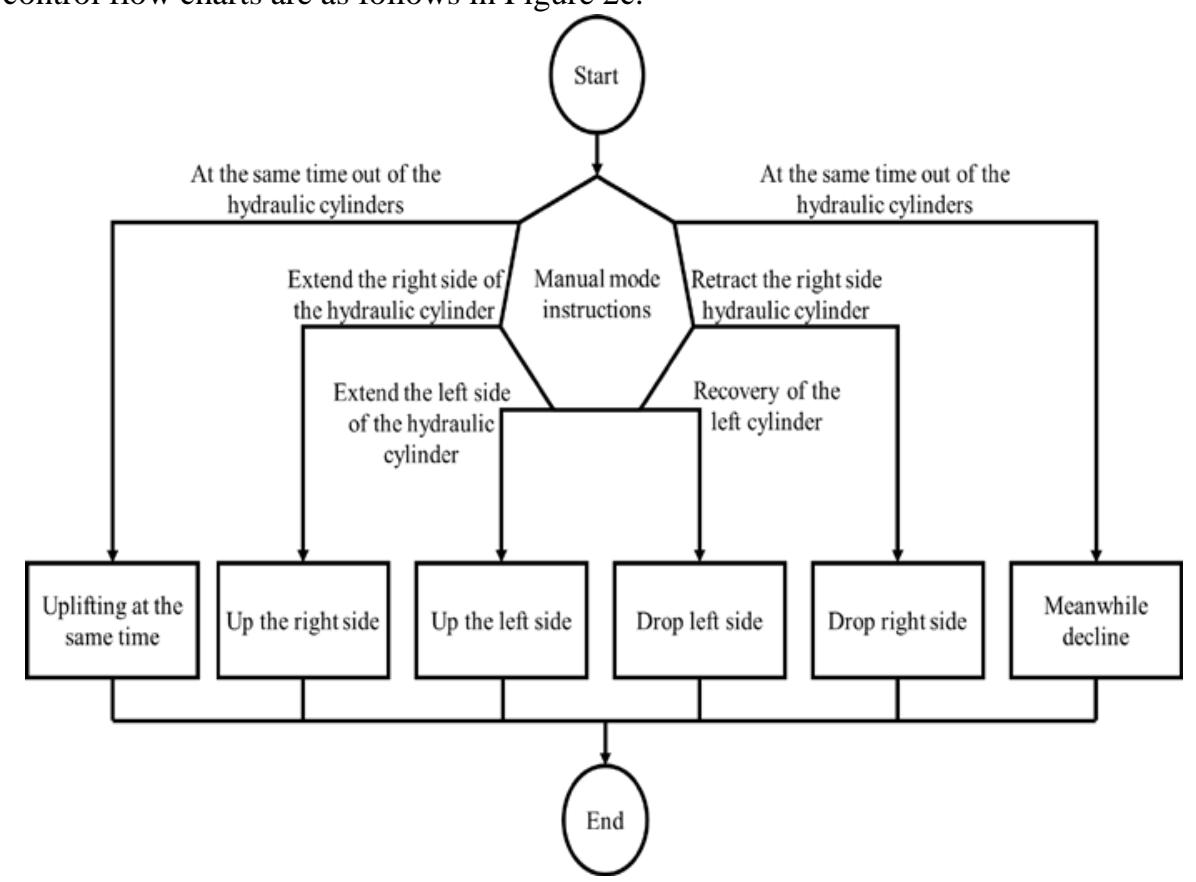

Fig.2c The manual flow and manual control flow charts

When the laser grader is in the automatic working state. The angle sensor first measures the inclination angle of the scraper and uploads it to the balance controller. The balance controller sends out the corresponding control signal so that the piston rod of the balance cylinder is extended or retracted to adjust the attitude so that the ground shovel Balanced state. Thereafter, the receiver receives the horizontal laser reference signal from the transmitter to detect the positional deviation of the ground shovel relative to the laser reference plane and converts the positional deviation signal into an electrical signal and transmits it to the microcontroller in the elevation controller for signal And then the height of the ground shovel is controlled by the electronic control line and the elevation hydraulic control device so that the height of the entire blade is reduced or higher than the laser reference plane when the height of the blade is lower than the laser reference plane. Positioning the elevation plane, in order to achieve the uneven ground or slope of the ground to fill the height of the leveling operation. The controller product picture is as follows in Fig.2d 


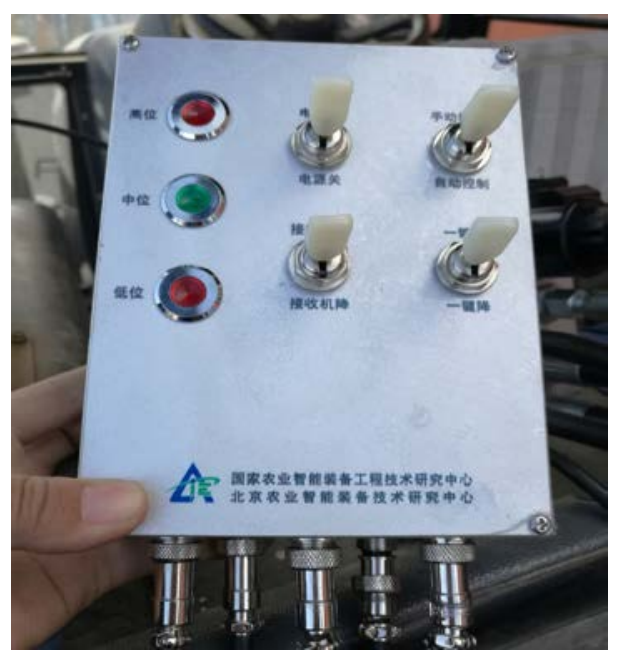

Fig.2d The product picture of controller

\section{System Test}

\subsection{Sensor PerformanceTest}

In order to verify the posture adjustment of the grader, a static test and a dynamic test were designed to test the stability and accuracy of the sensor adjustment. The attitude angle was collected using the SBG sensor during the test. To collect the static data, we need to calculate the arithmetic mean, maximum and minimum of the inclination angle, analyze the variability of the data with time. The smaller the deviation, the better the variability, the better the performance of the system regulation. The static attitude angle is shown in Fig 3a; the horizontal axis in the figure is the sampling time and the vertical axis is the attitude angle measurement. The mean and standard deviation of the statistical attitude angle data, the maximum error and the minimum error, and the error distribution frequency are shown in Table3-1, respectively.

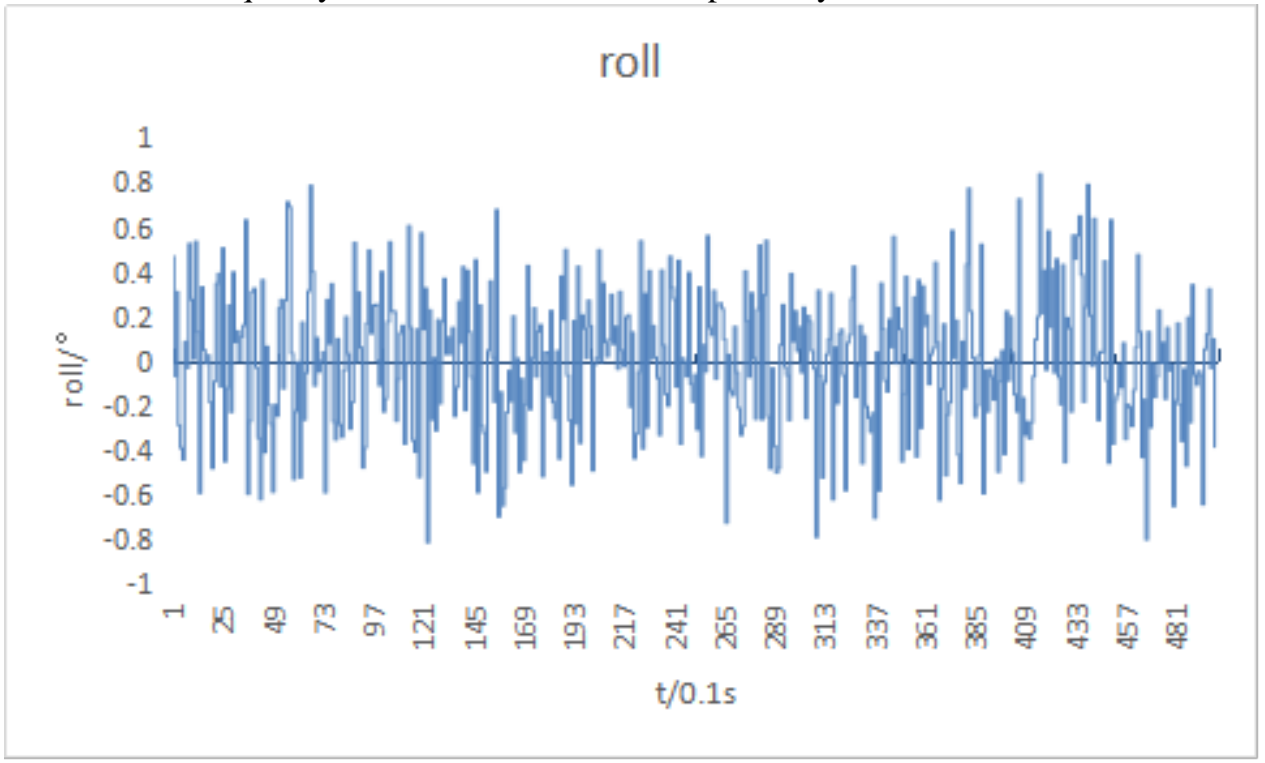

Fig. 3a The static attitude angle

Through the static data, we calculate the arithmetic mean, maximum and minimum of the inclination, all meet the requirements of the system, the variability of the data with time, the deviation is small, the variability is low and the system regulation performance is good. 
Table 3-1 The statistical attitude angle data

\begin{tabular}{cccc}
\hline & maximum $/{ }^{\circ}$ & minimum $/^{\circ}$ & arithmetic mean $^{\circ}$ \\
\hline roll & 0.8396 & -0.8163 & -0.0009 \\
\hline
\end{tabular}

Dynamic test is also through the change of attitude angle data to reflect the real-time system to adjust the performance. Dynamic test was conducted at Xiaotangshan Experimental Base in Beijing. In the homemade slope were carried out south and north to the laser level grader test, a total of 12 times. Table 3-2 records the attitude angle data and angular velocity of the posture sensor output frequency of $10 \mathrm{~Hz}$ with a filter factor of 0.1 , and Table 3-3 records the attitude angle data and the angular velocity of the attitude sensor output frequency 20HZ filter coefficient of 0.1 .

Table 3-2 The attitude angle data $(10 \mathrm{~Hz})$

\begin{tabular}{|c|c|c|c|c|c|}
\hline & & \multicolumn{2}{|c|}{ Roll } & \multicolumn{2}{|c|}{ Angular Velocity } \\
\hline & & $\begin{array}{c}\text { Arithmetic } \\
\text { Mean }\end{array}$ & $\begin{array}{l}\text { Standard } \\
\text { Deviation }\end{array}$ & $\begin{array}{l}\text { Arithmetic } \\
\text { Mean }\end{array}$ & $\begin{array}{c}\text { Standard } \\
\text { Deviation }\end{array}$ \\
\hline \multirow{3}{*}{ South } & 1 & 0.6287 & 1.9108 & -0.0371 & 4.4093 \\
\hline & 2 & 0.6526 & 2.2277 & -0.0128 & 4.7826 \\
\hline & 3 & 0.6934 & 2.3206 & -0.0406 & 4.7932 \\
\hline \multirow{3}{*}{ North } & 4 & 0.3776 & 1.6008 & 0.0056 & 2.9482 \\
\hline & 5 & 0.291 & 1.9263 & 0.0626 & 3.2196 \\
\hline & 6 & 0.9834 & 1.845 & 0.0514 & 4.4159 \\
\hline
\end{tabular}

Table 3-3 The attitude angle data $(20 \mathrm{~Hz})$

\begin{tabular}{cccccc}
\hline & \multicolumn{2}{c}{ Roll } & \multicolumn{2}{c}{ Angular Velocity } \\
\hline \multirow{3}{*}{ South } & & $\begin{array}{c}\text { Arithmetic } \\
\text { Mean }\end{array}$ & $\begin{array}{c}\text { Standard } \\
\text { Deviation }\end{array}$ & $\begin{array}{c}\text { Arithmetic } \\
\text { Mean }\end{array}$ & $\begin{array}{c}\text { Standard } \\
\text { Deviation }\end{array}$ \\
\cline { 2 - 6 } & 7 & 0.2483 & 2.1145 & -0.0062 & 4.2287 \\
\cline { 2 - 6 } & 8 & -0.0981 & 2.5209 & -0.1796 & 5.0385 \\
\hline \multirow{3}{*}{ North } & 9 & 0.0731 & 2.6474 & -0.061 & 5.4537 \\
\cline { 2 - 6 } & 10 & -0.2695 & 1.8906 & 0.0132 & 4.1404 \\
\cline { 2 - 6 } & 11 & -0.4617 & 1.866 & -0.0887 & 4.281 \\
\hline
\end{tabular}

Through the recording and analysis of the experimental data record, we obtained that the maximum degree of instantaneous adjustment of the inclination of the dynamic test at different frequencies can reach $8.65^{\circ}(10 \mathrm{HZ})$ and $10.33^{\circ}(20 \mathrm{HZ})$, the higher the frequency, the faster the adjustment, The more gentle.

\subsection{Analysis of Ground Conditions}

Farmland flatness can be used to measure the extent of field topography, reflecting the overall situation of farmland flatness. It is usually expressed by the standard deviation 
$\left(S_{d}\right)$ of the vertical distance of the ground surface relative to the surface to the fitting surface. The smaller the standard deviation, the less obvious the ground surface ups and downs, the more flat the ground; the greater the standard deviation, indicating that the farmland undulating ground, the more uneven the ground. Let the plane equation be fitted, then the vertical distance from the point to the fitting surface after interpolation is calculated as follows:

$$
Z=P X+Q Y+D
$$

Then the vertical distance of each point after the interpolation process to the fitting surface is calculated as follows:

$$
d_{j}=\frac{\left|P X_{j}+Q Y_{j}+D-Z_{j}\right|}{\sqrt{P^{2}+Q^{2}}}
$$

The average of all interpolation points to the fitting surface distance is:

$$
\bar{d}=\frac{1}{N} \sum_{j=1}^{N} d_{j}
$$

Then the standard deviation is calculated as follows:

$$
S_{d}=\sqrt{\frac{\sum_{j=1}^{N}\left(d_{j}-\bar{d}\right)^{2}}{N-1}}
$$

Table 3-4 is the use of conventional laser leveling and automatic adjustment device with laser leveling two different methods of field formation and improvement. The

\begin{tabular}{|c|c|c|c|c|}
\hline & $\begin{array}{c}\text { Before leveling } \\
\qquad S_{d} / \mathrm{cm}\end{array}$ & $\begin{array}{c}\text { After leveling } \\
\qquad S_{d} / \mathrm{cm}\end{array}$ & $\begin{array}{c}\text { Absolute } \\
\text { improvement } \\
\delta / \mathrm{cm} \\
\end{array}$ & $\begin{array}{c}\text { Relative } \\
\text { improvement } \\
\% \\
\end{array}$ \\
\hline $\begin{array}{c}\text { The } \\
\text { conventional } \\
\text { laser land } \\
\text { leveling } \\
\text { machine }\end{array}$ & 6.0 & 3.7 & 2.3 & 38.3 \\
\hline $\begin{array}{c}\text { Laser land } \\
\text { leveling } \\
\text { machine with } \\
\text { automatic } \\
\text { adjusting device }\end{array}$ & 6.0 & 2.6 & 3.4 & 56.7 \\
\hline
\end{tabular}
absolute improvement is the absolute magnitude of the improvement of the ground leveling condition.

Table3-4 Two different methods of field formation and improvement

The relative improvement degree is the ratio of the absolute improvement degree to the pre-level land area, and the relative degree of the improvement of the ground leveling condition is reflected. The experimental base for the Beijing Xiaotangshan 
experimental base, the plot area of 2 hectares. Figure.3b shows the self-balancing adjustment of the graders

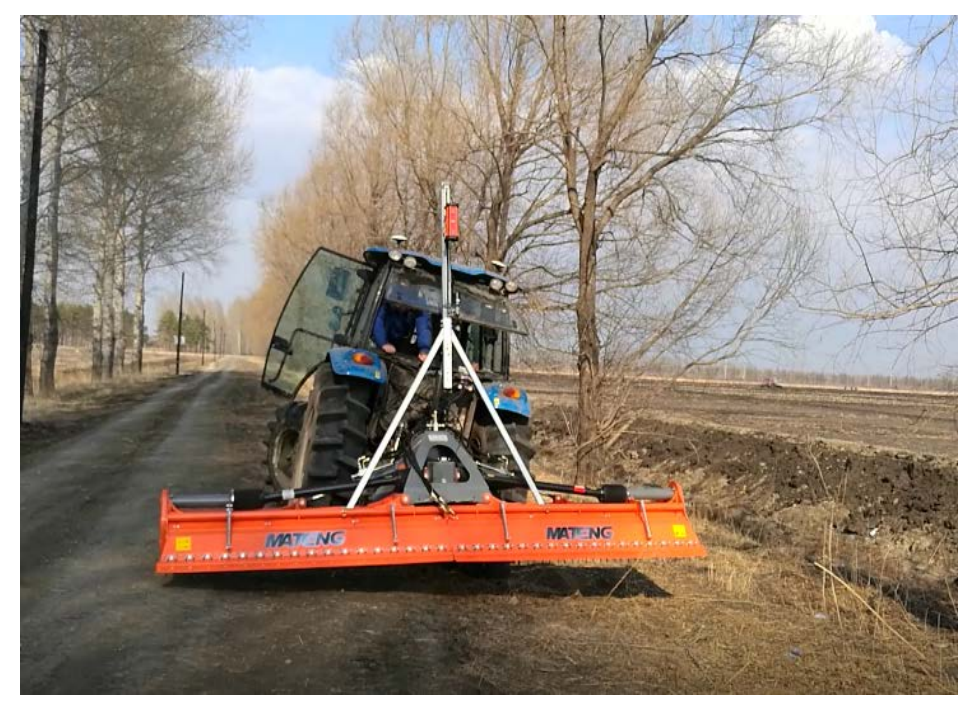

Fig. 3b The self-balancing adjustment of the graders

According to the standard deviation of the elevation before and after land formation, it can be calculated that the absolute improvement degree of land before and after leveling is increased by $47.8 \%$, the relative improvement degree is $18.6 \%$ and the land error level is less than $1 \%$.

\section{Conclusion}

1) The developed laser leveling system consists of laser transmitter and receiver, flat shovel, flat shovel hydraulic system and controller and other components. Among them, the design of the laser receiver to achieve flat leveling automatic leveling function.

2) The device not only has the existing wide range of elevation adjustment and with a horizontal balance adjustment, to achieve a single level of precision ground leveling, agricultural equipment to achieve high efficiency and high precision requirements.

3) With this controller, the absolute improvement in land formation is increased by $47.8 \%$, the relative improvement is $18.6 \%$, and the land altitude intercept is less than $1 \%$.

\section{Acknowledgements}

Public welfare industry (agriculture) special 'special fund for Agro-scientific research in the Public Interest'- Northeast spring corn one-time fertilization key technology research and integration (2016-2017) (201303103) ;

The Key Research And Development Program of Shandong Province (2016CYJS03A01-1);

Ministry of Agriculture 948 project - precision agriculture intelligent key equipment technology introduction and innovation (2016-2017) (2016-X26) 


\section{References}

1. Si Yongsheng, et al. Design of Control System of Laser Leveling Machine Based on Fussy Control Theory. Ifip Tc 12 International Conference on Computer and Computing Technologies in Agriculture 2007:1121-1127.

2. Han Bao. Development of 1JPY-3.0 laser controlled compositive leveling machine. Transactions of the Chinese Society of Agricultural Engineering 2003.

3. Ito, N, H. Takahashi, and Y. Torigoe. Effect of traffic compaction by the leveling machine with a laser beam control system on transplanting accuracy of rice seedlings. Tohoku Agricultural Research 1994.

4. Hiroshi, Osari. CiNii Articles - Laser land leveling machine. Transactions of the Japanese Society of Irrigation

5. Ayer, H. Laser leveling and farm profits. Farmline U.s.dept.of Agriculture Economic Research Service 1982.

6. Munroe, Jay R. Rotary laser level with automated level calibration. 2015.

7. Delsignore, Gianmario. LASER CONTROLLED LAND LEVELLING MACHINE. 2010.

8. Masoumi, et al. DESIGN, DEVELOPMENT AND EVALUATION OF A DEPTHCONTROLLER FOR LASER LAND-LEVELING. Acta Horticulturae 1054(2014):285290.

9. Tanabe, Yoshio, et al. Development of Japanese style farm machines and implements for a laser-land leveling. 2004.

10. Mohamed, Mohamed Gafar Bakhiet. Evaluation of Laser Land Leveling in Sugarcane Production in Assalaya Sugar Scheme - Sudan. 2015.

11. Takahashi, et al. Performance of semiautomatic leveling machine with use of laser beams. Tohoku Agricultural Research 1993.

12. Asif, Muhammad, et al. Wheat Productivity, Land and Water Use Efficiency by Traditional and Laser Land-leveling Techniques. Journal of Biological Sciences 3.2(2003).

13. Kimura, et al. Performance of automatic leveling machine with use of laser beams and effect of smooth leveling on the rice plant growth. Tohoku Agricultural Research 1994. 
